therapeutic strategies against the mTOR-reinforced NAFLDassociated HCC.

This project is supported by Collaborative Research Fund (C4045-18W) and the AstraZeneca Preclinical Oncology Research Program (2017).

\section{IDDF2019-ABS-0229 BIOCHEMICAL AND MOLECULAR EFFECTS OF $17 \beta$ ESTRADIOL ON MEMBRANE FUNCTIONS IN AGED RAT LIVER}

Pardeep Kumar*. Jawaharlal Nehru University, India

\subsection{6/gutjnl-2019-IDDFabstracts. 101}

Background Free radical production and oxidative stress are known to increase in the liver during aging and may contribute to the oxidative damage. Aging in females and males is considered as the end of natural protection against age-related diseases like osteoporosis, coronary heart disease, diabetes, Alzheimer's disease, and Parkinson's disease. These changes increase during the menopausal condition in females when the level of estradiol is decreased.

The objective of this study was to observe the changes in activities of membrane-linked ATPases $\left(\mathrm{Na}^{+} / \mathrm{K}{ }^{+}\right.$ATPase, $\mathrm{Ca}^{2}$ + ATPase), antioxidant enzymes (superoxide dismutase, glutathione-S-transferase), lipid peroxidation levels, lipofuscin content, glucose transporters 2 (GLUT 2) expression and membrane fluidity occurring in livers of female rats of 3, 12 and 24 months age groups, and to see whether these changes are restored to 3 months control levels rats after exogenous administration of $17-\beta$-estradiol (E2).

Methods The aged rats (12 and 24 months old) ( $n=8$ for each group) were given subcutaneous injection of $17 \beta$ estradiol $(0.1 \mathrm{ug} / \mathrm{g}$ body weight) daily for one month. Controls animals received an equal volume of vehicle. After 30 days of hormone treatment, experimental animals of all the groups were sacrificed and livers were isolated for further study. A detailed study was carried on membrane linked enzymes, membrane fluidity, lipofuscin and GLUT2 expression with immunohistochemistry to identify the antiaging role of E2 using biochemical, molecular and histochemical study.

Results The results obtained in the present work revealed that normal aging was associated with significant decrease in the activities of membrane-linked ATPases, antioxidant enzymes, membrane fluidity, GLUT 2 expression and an increase in lipid peroxidation and lipofuscin content in livers of aging female rats. Our data showed that exogenous administration of E2 brought these changes to near normalcy in aging female rats.

Conclusions The present study showed that E2 treatment reversed the changes to normal levels. E2 treatment may be beneficial in preventing some of the age-related changes in the liver by increasing antioxidant defenses.

\section{IDDF2019-ABS-0230 CHANGE IN THE LIPID PROFILE, LIPOGENIC AND RELATED ENZYMES IN THE LIVERS OF EXPERIMENTAL DIABETIC RATS: EFFECT OF TRIGONELLA FOENUM GRAECUM AND VANADATE}

Pardeep Kumar*, Najma Baquer. Jawaharlal Nehru University, India
Background Diabetes has been considered as one of the fastest growing epidemic worldwide; the number of people with diabetes is estimated to increase from 381.8 million in 2013 to 591.9 million in 2030. Oxidative stress in diabetic tissues is accompanied by a high level of free radicals and the simultaneously declined antioxidant enzymes status leading to cell membrane damage.

In the present study, the effect of sodium orthovanadate (SOV) and Trigonella foenum graecum seed powder (TSP) administration has been studied on hepatic glucose homeostasis, lipogenic enzymes and lipid metabolism in liver tissues of the alloxan-induced diabetic rats and to see whether the treatment with SOV and TSP is capable of reversing these effects.

Methods Diabetes was induced by administration of alloxan monohydrate $(15 \mathrm{mg} / 100 \mathrm{gm} \mathrm{b.wt}$.) and rats were treated with 2IU insulin, $0.6 \mathrm{mg} / \mathrm{ml} \mathrm{SOV}, 5 \%$ TSP in the diet and a combination of $0.2 \mathrm{mg} / \mathrm{ml} \mathrm{SOV}$ with $5 \%$ TSP separately for 21 days. Control animals were given only the vehicle. The activities of two lipogenic enzymes, glucose-6-phosphate dehydrogenase and malic enzyme; and related enzymes, hexokinase and glucose-6-phosphatase were measured in the liver cytosolic fractions of diabetic rats and diabetic rats treated separately with TSP and SOV. The total lipids, triglycerides and cholesterol levels were estimated in the livers of the diabetic and the treated rats.

Results Diabetic rats showed hyperglycemia with almost fourfold high blood glucose levels. The activities of both the lipogenic enzymes and hexokinase isozymes were significantly decreased whereas the activity of glucose-6-phosphatase was significantly increased in the diabetic liver. During diabetes, the levels of total lipids and triglycerides increased significantly with a decrease in the cholesterol levels in the liver. TSP and SOV were able to restore the altered enzyme activities to almost control levels. Rats treated with the combined dose of SOV and TSP had glucose levels comparable to controls, similar results were obtained with the triglycerides and cholesterol levels in the liver of diabetic rats.

Conclusions Our results showed that lower doses of SOV $(0.2$ $\mathrm{mg} / \mathrm{ml}$ ) could be used in combination with TSP to effectively counter diabetic alterations without any toxic side effects.

\section{IDDF2019-ABS-0234 ROLE OF MOMORDICA CHARANTIA FRUIT EXTRACT AGAINST HEPATIC FIBROSIS INDUCED BY CARBON TETRACHLORIDE IN RATS}

Sanjay Kumar*, Rajender Khanna. Vivekananda Global University, India

10.1136/gutjnl-2019-IDDFabstracts. 103

Background Momordica charantia Linn. (Karela) commonly known as Bitter melon or Bitter gourd is a tropical and subtropical climber of the family Cucurbitaceae. Its fruit is also used for the treatment of diabetes and related conditions amongst the indigenous populations of Asia, South America, India and East Africa.

The aim of the present study was to investigate the Momordica charantia fruit (MCF) extract as hepatoprotective agent verse hepatic damages caused by carbon tetrachloride $\left(\mathrm{CCl}_{4}\right)$.

Methods Male Wistar albino rats were divided into two equal groups $(n=8)$ and treated as follows: Group 1, kept as control group and orally given saline; Group 2, kept as control 